Check for updates

Cite this: RSC Adv., 2017, 7, 46553

Received 8th August 2017

Accepted 10th September 2017

DOI: $10.1039 / c 7 r a 08744 f$

rsc.li/rsc-advances

\section{Synthesis of $\mathrm{Ni} / \mathrm{Co} / \mathrm{Al}$-layered triple hydroxide abrominated graphene hybrid on nickel foam as electrode material for high-performance supercapacitors $\dagger$}

\begin{abstract}
Maher Jabeen,\$ Muhammad Ishaq, (ID \$ Weiming Song, * Liyang Xu and Qigang Deng*
The determined need for a sustainable energy economy has evoked the increasing interest of researchers concerning the discovery of smart material designs of layered double hydroxide (LDH) nanocomposites for energy-based applications. This paper presents a novel method for the direct growth of brominated graphene and layered triple hydroxide (LTH) on 3D nickel foam (NF) as a supercapacitor electrode by a facile one-step in situ crystallization hydrothermal method. Subsequently, the as-synthesized NCALaBG-NF hybrids were characterized by TEM, SEM, HRTEM, XRD, FT-IR, RAMAN, XPS, and EDS. Moreover, the electrochemical performance disclosed that by fine-tuning the $\mathrm{Ni} / \mathrm{Co} / \mathrm{Al}$ mole ratios, it was possible to obtain optimized ratio of NCA-L@BG-NF-3 to display the maximum specific capacity of $1998 \mathrm{C} \mathrm{g}^{-1}$ at $6 \mathrm{~A} \mathrm{~g}^{-1}$, excellent rate capability of $75.3 \%$ at $20 \mathrm{~A} \mathrm{~g}^{-1}$, and excellent cyclic stability of $\sim 91 \%$ capacitance retention after 2000 cycles at $20 \mathrm{~A} \mathrm{~g}^{-1}$ with $100 \%$ coulombic efficiency. Furthermore, the greater electrochemical performance of LTH was achieved and synergistically strengthened with a high surface area provided by the conducting brominated graphene oxide framework directly grown on a 3D porous NF to form a binder-free electrode, which could improve the electrochemical performance in terms of charge transport and storage. Accordingly, these remarkable properties show that NCA-L@BGNF-3 may be considered as a promising candidate for high-performance supercapacitor applications.
\end{abstract}

\section{Introduction}

Recently, considerable attention has been paid to the continuously increasing global energy needs and the limited availability of fossil fuels as well as the exploration of renewable energy and of high-performance energy storage systems, such as batteries, ${ }^{1}$ fuel cells, ${ }^{2}$ and supercapacitors (SCs). ${ }^{3}$ In this regard, layered double hydroxides (LDHs) have been gaining importance in recent years. In particular, they are considered as unusual layered materials and a class of lamellar compounds ${ }^{4}$ consisting of positively-charged hydrotalcite-like layers with a weakly bound charge compensating the anions in the interlayer region, ${ }^{5}$ which have potential as positive electrode materials. ${ }^{6}$ LDHs normally have the general formula $\left[\mathrm{M}_{1-x}^{\mathrm{II}} \mathbf{M}_{x}^{\mathrm{III}} x(\mathrm{OH})_{2}\right]^{x+}\left[\mathrm{A}^{n-}\right]_{x / n} \cdot m \mathrm{H}_{2} \mathrm{O}$, where $\mathrm{M}^{\mathrm{II}}$ and $\mathbf{M}^{\mathrm{III}}$ denote the layers of divalent and trivalent metallic cations, respectively, and $\mathrm{A}^{n-}$ is an interlayer anion, which can be almost any organic or inorganic anion. ${ }^{7}$ Moreover, due to the layered structure in

College of Chemistry and Chemical Engineering, Qiqihar University, 42, Wenhua Street, Qiqihar, Heilongjiang 161006, P. R. China. E-mail: qdsongweiming@163. com; Tel: +864522742594

$\dagger$ Electronic supplementary information (ESI) available. See DOI: 10.1039/c7ra08744f

\$ The first two authors contributed equally.
LDHs, they usually possess a high specific surface area, which can facilitate fast ion transfer. This offers them great superiority in many electrochemical fields. ${ }^{8}$ However, the electrochemical performances of LDHs are hindered by their low power density, poor electrical conductivity, low mechanical stability, and poor cycle life. ${ }^{9}$ To overcome these limitations and to maximize the capacitance, an efficient incorporation of a versatile class of nanomaterials with a substantial amount of active sites for ion and electrolyte transport in redox reactions is highly favorable. ${ }^{\mathbf{1 0}}$ In this regard, materials such as activated carbon, carbon nanotubes (CNTs), graphene, and graphene oxide (GO) with large surface area, high electrical conductivity, ${ }^{\mathbf{1 1}}$ and excellent electrochemical stability have been used to hybridize with LDHs. ${ }^{12}$ However, previous studies have fallen short of examining the LDH hybridized with halogenated graphene grown directly on nickel foam for improving the electrochemical behavior.

Several studies have suggested using brominated graphene (BG), which is a type of graphene derivative obtained through the direct structural transformation of $\mathrm{C}-\mathrm{C}$ bonds of graphene from $\mathrm{sp}^{2}$ to $\mathrm{sp}^{3}$ configuration. This is an efficient strategy to create derivatives of graphene, in which bromine atoms are functionalized on carbon nanosheet skeletons covalently. ${ }^{13}$ The literature on BG shows a variety of approaches to achieve BG. 
Jankovsk et al. discussed the properties of graphene that could be tailored through chemical modifications, such as hydrogenation or halogenation. The halogen-based chemically modified graphene material exhibited many unique properties. Brominated graphene is a highly favorable starting material for the synthesis of other graphene derivatives due to the highly reactive $\mathrm{C}-\mathrm{Br}$ bonds. ${ }^{\mathbf{1 4}}$ Nevertheless, to the best of our knowledge, almost no studies have been centered on the hybridization of BG with LDHs. Peng et al. synthesized fluorinated graphene/Co-Al-LDH composites as electrode materials for supercapacitors, which exhibited the highest specific capacitance of $1222 \mathrm{~F} \mathrm{~g}^{-1}$ at $1 \mathrm{~A} \mathrm{~g}^{-1}$ and the best rate capability. ${ }^{15} \mathrm{Wu}$ et al. reported a hybrid structure consisting of a chemically converted graphene-encapsulated carbon@nickel-aluminum LDH high-energy supercapacitor, which could deliver a high energy density of $35.5 \mathrm{~W} \mathrm{~kg}^{-1}$ at $670.7 \mathrm{~W} \mathrm{~kg}^{-1}$ power density at $1 \mathrm{~A} \mathrm{~g}^{-1}$ with an excellent rate capability. ${ }^{\mathbf{1 6}}$

On the other hand, LDH powder, which is usually used for binder-enriched electrodes prepared by the conventional slurrycoating technique, has been mixed with a conducting agent and binder and then coated on nickel foam (NF) to form electrodes. ${ }^{17,18}$ Consequently, the addition of a polymeric binder reduces the inclusive performance of the SCs by hindering the charge transport rate and increasing the total mass of the electrode. However, the tedious preparation steps have a great influence on the electrochemical performance. In addition, the contact and electrical conductivity between the LDH and NF are poor. In this context, modern research has focused on growing LDHs with interconnected architecture directly on a conductive substrate to form a binder-free electrode for supercapacitors, which could act as a promising substrate in LDH-based SCs. This is because the such an architecture can reduce the intensive accumulation of $\mathrm{LDH}$, allowing maximum use of the active materials, while the $3 \mathrm{D}$ porous NF provides more channels to facilitate rapid penetration of the electrolyte ions into the active LDH materials of the electrodes compared to that achievable with the common slurry-coating technology. ${ }^{\mathbf{1 9 , 2 0}}$

Inspired by the above findings, in this study, we explore the possibility of loading BG layers onto the surface of Ni/Co/AlLTH, which in turn can be grown directly on NF as a binderfree SC electrode by a one-step in situ crystallization hydrothermal method. Compared with pure NCA-L and NCA-L@G$\mathrm{NF}$, the electrochemical performance reveals that by finetuning the $\mathrm{Ni} / \mathrm{Co} / \mathrm{Al}$ mole ratio, the optimized ratio of NCAL@BG-NF-3 hybrid exhibited the highest specific capacity. These impressive results revealed a great promise for application of the NCA-L@BG-NF-3 hybrid in SCs, which could achieve the best rate capability and the most stable capacitance retention, making it one of the most promising electrode materials for SCs.

\section{Experimental section}

\subsection{Materials and chemicals}

Natural graphite powder $(<45 \mu \mathrm{m}, \geq 99.99 \%)$, concentrated sulfuric acid $\left(\mathrm{H}_{2} \mathrm{SO}_{4}, 98.08 \%\right)$, sodium nitrate $\left(\mathrm{NaNO}_{3}\right)$, hydrogen peroxide $\left(\mathrm{H}_{2} \mathrm{O}_{2}, 30 \%\right)$, and potassium permanganate
$\left(\mathrm{KMnO}_{4}\right)$ were used to synthesize the GO. $\mathrm{Ni}\left(\mathrm{NO}_{3}\right)_{2} \cdot 6 \mathrm{H}_{2} \mathrm{O}$, $\mathrm{Al}\left(\mathrm{NO}_{3}\right)_{3} \cdot 6 \mathrm{H}_{2} \mathrm{O}, \mathrm{CoCl}_{2} \cdot 6 \mathrm{H}_{2} \mathrm{O}$, urea, ethanol ( 99.5\%), $\mathrm{HCl}$, and nickel foam were used to synthesize the LTH-NF. For the bromination of GO, HBr was used. All the chemicals were obtained from Sinopharm Chemical Reagent Co. Ltd (Shanghai, China). All of the materials were without further purification. All the solutions were prepared using Milli-Q water $(18.25 \mathrm{M} \Omega \mathrm{cm}$ resistivity) as the solvent.

\subsection{Preparation of GO and suspension of BGO}

Graphene oxide (GO) was synthesized according to Hummers method reported in our previous study. ${ }^{21}$ The brominated graphene oxide suspension (BGO) was prepared from the asprepared GO in the following typical procedure. First, $100 \mathrm{mg}$ $\left(1 \mathrm{mg} \mathrm{ml}{ }^{-1}\right)$ of GO powder was dispersed in $100 \mathrm{ml}$ of deionized water via a high-shear homogenizer (FLUKO, Germany) at $1000 \mathrm{rpm}$ for $3 \mathrm{~min}$. Next, the GO suspension was exfoliated via a Sonics ultrasonic processor $(750 \mathrm{~W}, 40 \mathrm{kHz})$ with $40 \%$ amplitude for $10 \mathrm{~min}$. Then, $4 \mathrm{ml}$ of $\mathrm{HBr}$ was mixed with the GO suspension. After ultrasonic dispersion by an ultrasonic bath for $10 \mathrm{~min}$, the mixture was stirred for $2 \mathrm{~h}$.

\subsection{Precleaning of the nickel foam (NF)}

Prior to these chemical processes, NF $(1 \mathrm{~cm} \times 3 \mathrm{~cm})$ was cleaned consecutively in $6 \mathrm{M} \mathrm{HCl}$, DI water, and ethanol with ultrasonication. Following this, the NF was dried at $60{ }^{\circ} \mathrm{C}$ for $12 \mathrm{~h}$ in a vacuum oven.

\subsection{Preparation of the Ni/Co/Al-LTH@BG hybrid on nickel foam (NCA-L@BG-NF)}

We designed a new technique for the synthesis of NCA-L@BG-NF by the in situ crystallization of metal nitrate using brominated graphene (BG) suspension and NF precursors followed by a singlestep hydrothermal process. First, $0.005 \mathrm{M}$ of $\mathrm{Ni}\left(\mathrm{NO}_{3}\right)_{2} \cdot 6 \mathrm{H}_{2} \mathrm{O}$, $0.005 \mathrm{M} \mathrm{CoCl}_{2} \cdot 6 \mathrm{H}_{2} \mathrm{O}$, and $0.005 \mathrm{M} \mathrm{Al}\left(\mathrm{NO}_{3}\right)_{3} \cdot 6 \mathrm{H}_{2} \mathrm{O}$ were dissolved in $75 \mathrm{ml}$ of deionized water and stirred for $2 \mathrm{~h}$. Subsequently, $1.5 \mathrm{~g}$ of urea was added to the solution and the entire solution was stirred vigorously with a magnetic stirrer for another $0.5 \mathrm{~h}$. Then, $20 \mathrm{ml}$ of the as-prepared BG suspension was mixed into the LTH mixture via stirring for another $0.5 \mathrm{~h}$. The entire solution was then transferred to a $100 \mathrm{ml}$ Teflon-lined autoclave and a piece of cleaned $\mathrm{Ni}$ foam was dipped into the solution. The autoclave was heated to $150{ }^{\circ} \mathrm{C}$ for $12 \mathrm{~h}$. After the reaction was complete, the autoclave was cooled to room temperature. Finally, the Ni foam was washed successively with DI water and ethanol and dried at $60{ }^{\circ} \mathrm{C}$ for $12 \mathrm{~h}$ in a vacuum oven. Three different compositions of LTH were prepared by keeping $\mathrm{Ni}\left(\mathrm{NO}_{3}\right)_{2}$ constant and varying the $\mathrm{Al}\left(\mathrm{NO}_{3}\right)_{3}: \mathrm{CoCl}_{2}$ mole ratios for the initial feeding, such as $1: 1: 1,1: 2: 2$, and $1: 3: 3$; the final composites were labeled as NCA-L@BG-NF-1, NCA-L@BG-NF-2, and NCA-L@BG-NF-3, respectively. The weights of the deposited materials were determined gravimetrically by measuring the change in weight of the nickel foam before and after the material deposition. The mass of the active material on the NF was about $1.5 \mathrm{mg}$. For comparison, NCA-L-NF and NCA-L@G-NF were fabricated in the absence of BG 
with the same experimental conditions on nickel foam as binderfree electrodes.

\subsection{Characterization}

The surface morphology, structure, and composition of the samples were investigated by scanning electron microscopy (SEM) (JEOL JSM6480A microscope), transmission electron microscopy (TEM, JEM-2100F), and by high-resolution transmission electron microscopy (HRTEM, JEOL 2010). The crystallographic structures of the samples were determined by X-ray diffraction (XRD) (Rigaku TTR-III) equipped with $\mathrm{Cu} \mathrm{K} \alpha$ radiation $(\lambda=0.15406 \mathrm{~nm})$. Fourier transform infrared spectra (FTIR) of the samples were recorded in the range $4000-500 \mathrm{~cm}^{-1}$ with $2 \mathrm{~cm}^{-1}$ resolution using the $\mathrm{KBr}$ pellet technique on a Nexus FT-IR spectrophotometer (Thermo Nicolet, USA). Raman spectra were collected using an INVIA spectrophotometer (Renishaw, UK). X-ray photoelectron spectroscopy (XPS) measurements were done on a KRATOA XSAM800 XPS system with $\mathrm{Mg} \mathrm{K} \alpha$ source.

\subsection{Electrical and electrochemical performances}

All the electrochemical measurements of the NCA-L-NF, NCAL@G-NF and NCA-L@BG-NF, deprived of any additive/binder, with three different mole ratios were carried out on a $\mathrm{CHI}$ 660E (Chenhua, Shanghai, China) electrochemical workstation using a common three-electrode cell. The electrochemical measurements were made in $6 \mathrm{M} \mathrm{KOH}$ electrolyte at room temperature. Herein, all the prepared samples were used as working electrodes, while a platinum foil and a saturated calomel electrode (SCE) were used as the counter and reference electrodes, respectively. Their proposed applications could be implemented with much discretion using cyclic voltammetry (CV). The voltammetric measurements were carried out within a potential range of 0 to $0.6 \mathrm{~V}$ ( $v s$. SCE) at different scan rates of $5,10,20,40$ and $50 \mathrm{mV} \mathrm{s}^{-1}$, respectively. The cycle life was tested on a LAND CT2001A test system through a galvanostatic charge-discharge technique, and the cycling performances of the obtained electrode materials were explored. GCD curves were measured at different current densities 6, 8, 10, 15 and $20 \mathrm{~A} \mathrm{~g}^{-1}$, respectively in the potential range of $0-0.55 \mathrm{~V}$ ( $v s$. SCE). Cycle stability measurements were tested at $20 \mathrm{~A} \mathrm{~g}^{-1}$ for 2000 cycles. Electrochemical impedance measurement (EIS) data were collected in the frequency range from $100 \mathrm{kHz}$ to $0.01 \mathrm{~Hz}$ at an open circuit potential with an AC voltage amplitude of $5 \mathrm{mV}$. The specific capacity $\left(\mathrm{C}^{-1}\right)$ of the prepared sampleelectrodes based on the galvanostatic discharge curve was computed using the following equation: ${ }^{22}$

$$
Q=I \Delta t / m
$$

where $I(\mathrm{~mA})$ is the discharge current, $m(\mathrm{mg})$ is the mass of the active materials in the electrode, and $\Delta t(\mathrm{~s})$ is the discharge time.

\section{Results and discussion}

\subsection{Structural characterization of electrode material}

The choice of material and its synthesis is extremely important when fabricating high-performance electrode materials. In view of the importance of LDHs, we prepared a fascinating combination of $\mathrm{Ni}$, Co, and $\mathrm{Al}$ layered triple hydroxides (LTHs) by directly growing on nickel foam hybridized with a BGfunctionalized graphene layer as a promising electrode material. To account for the formation of NCA-L@BG-NF and the robust adhesion on nickel foam, we present the schematic of the growth mechanism in Fig. 1. To describe the possible formation mechanism of the NCA-L@BG-NF, we referred to the Ostwald ripening and self-assembling mechanism, which involves the nucleation and growth of NCA-L crystals; at the same time under the same temperature, the LTH was hydrothermally hybridized with $\mathrm{BG}$ on nickel foam. ${ }^{23}$ Initially as shown in the schematic in Fig. 1, Ni, Co, and Al metal salts in water were magnetically stirred to enable their dispersion; simultaneously, GO and $\mathrm{HBr}$ were also magnetically stirred together in order to obtain the functionalized BG (step I). This leads to an in situ release of $\mathrm{OH}^{-}$and $\mathrm{CO}_{3}{ }^{2-}$ at a controlled rate from urea decomposition, which further initiates the precipitation of $\mathrm{Ni}^{2+}, \mathrm{Co}^{2+}$, and $\mathrm{Al}^{3+}$ (ref. 24) (step II). Simultaneously, $\mathrm{Ni}^{2+}, \mathrm{Al}^{3+}$, and $\mathrm{Co}^{2+}$ from $\mathrm{Ni}\left(\mathrm{NO}_{3}\right)_{2}, \mathrm{CoCl}_{2}$, and $\mathrm{Al}\left(\mathrm{NO}_{3}\right)_{3}$ get mixed with $\mathrm{NH}_{3}$, which leads to the formation of an amine complex. The high specific surface area of BG makes it easy to adsorb a large number of amine complexes of $\mathrm{Ni}^{2+}, \mathrm{Co}^{2+}$, and $\mathrm{Al}^{3+}$. Such amine complex metal ions easily get adsorbed on the heterogeneous surface of the substrate (NF) hydrothermally, or by electrostatic, or van der Waals forces (step III). Initially, the solution was neutral but with time and increasing temperature, the solution becomes alkaline. At this condition, the $\mathrm{Ni}\left(\mathrm{NH}_{3}\right)_{4}{ }^{2+}, \mathrm{Co}\left(\mathrm{NH}_{3}\right)_{4}{ }^{2+}$, and $\mathrm{Al}\left(\mathrm{NH}_{3}\right)_{2}{ }^{3+}$ are unstable and the following reactions occur to form mixed metal hydroxides. Then, nucleation and growth occurs through an aggregationbased mechanism, to produce crystals with hierarchical architectures that contribute to the final structure of the electrode. ${ }^{25}$

$$
\begin{aligned}
& \mathrm{CO}\left(\mathrm{NH}_{2}\right)_{2}+\mathrm{H}_{2} \mathrm{O} \rightarrow 2 \mathrm{NH}_{3}+\mathrm{CO}_{2}(\text { Step I }) \\
& \mathrm{NH}_{3}+\mathrm{H}_{2} \mathrm{O} \rightarrow \mathrm{NH}_{4}^{+}+\mathrm{OH}^{-} \\
& \mathrm{CO}_{2}+\mathrm{H}_{2} \mathrm{O} \rightarrow \mathrm{CO}_{3}^{2-}+2 \mathrm{H}^{+} \\
& \mathrm{Ni}^{2+}+\mathrm{NH}_{3} \rightarrow \mathrm{Ni}\left(\mathrm{NH}_{3}\right)_{4}{ }^{2+}(\text { Step II) } \\
& \mathrm{Co}^{2+}+\mathrm{NH}_{3} \rightarrow \mathrm{Co}\left(\mathrm{NH}_{3}\right)_{4}{ }^{2+} \\
& \mathrm{Al}^{3+}+\mathrm{NH}_{3} \rightarrow \mathrm{Al}\left(\mathrm{NH}_{3}\right)_{6}^{3+} \\
& \mathrm{Ni}\left(\mathrm{NH}_{3}\right)_{4}{ }^{2+}+2 \mathrm{OH}^{-} \rightarrow \mathrm{Ni}(\mathrm{OH})_{2}+4 \mathrm{NH}_{3}(\text { Step III }) \\
& \mathrm{Co}\left(\mathrm{NH}_{3}\right)_{4}{ }^{2+}+2 \mathrm{OH}^{-} \rightarrow \mathrm{Co}(\mathrm{OH})_{2}+4 \mathrm{NH}_{3} \\
& \mathrm{Al}\left(\mathrm{NH}_{3}\right)_{6}{ }^{3+}+3 \mathrm{OH}^{-} \rightarrow \mathrm{Al}(\mathrm{OH})_{3}+6 \mathrm{NH}_{3}
\end{aligned}
$$



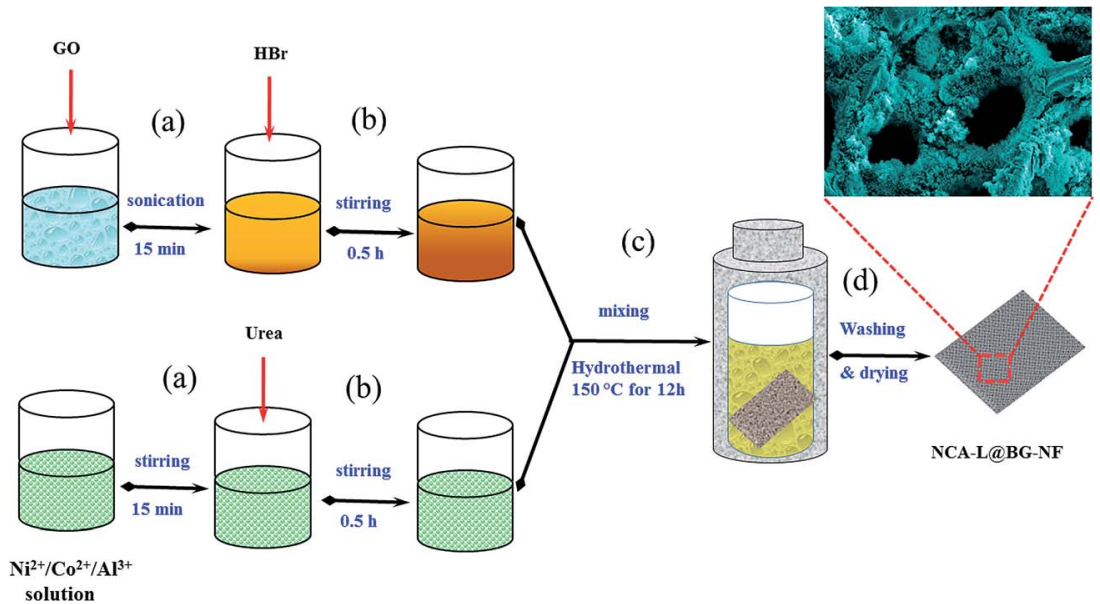

Fig. 1 Schematic representation of the formation mechanism of NCA-L@BG-NF.

\subsection{Morphology and structural characterization}

The hierarchical configuration of the NCA-L-powder, NCA-L-NF, NCA-L@BG-NF-3 sample electrodes were investigated by scanning electron microscopy (SEM) and transmission electron microscopy (TEM) at different magnifications as shown in Fig. 2. In a few studies reported in the literature, the SEM images of LTH samples, usually prepared by predictable methods, exhibit hexagonal-plate and flower-like morphologies. ${ }^{26}$ In case of this study, we observe that the 3D hierarchical NCA-L-powder has identical thin hexagonal flacks arranged in a flower-like morphology, during the hydrothermal process Fig. 2a and b. ${ }^{7}$ Fig. S1 $\uparrow$ shows an SEM image of the bare $\mathrm{NF}$, which has an even surface providing a high specific surface area (110PPI), with a microporous structure that enables sufficient loading of LTH materials per unit area. ${ }^{27,28}$ Fig. $2 \mathrm{c}$ and d present the decoration of NCA-L on NF with a flower-like morphology. Fig. 2e and f show that the surface of the NF was
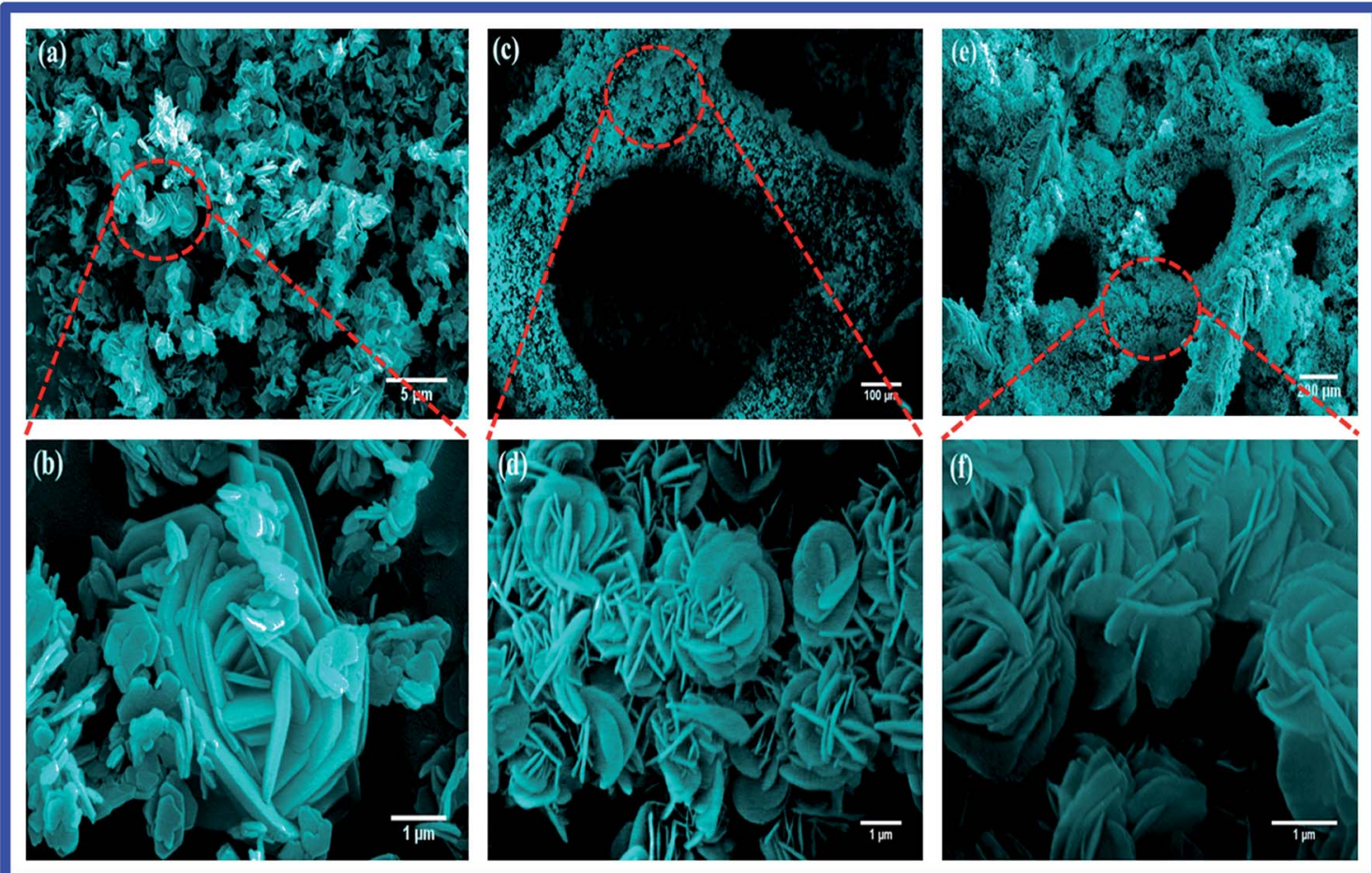

Fig. 2 SEM analysis: (a, b) low and high resolution SEM images of NCA-L powder showing a rose-like morphology, (c, d) NCA-L-NF, and (e, f) NCA-L@BG-NF-3, respectively. 
covered completely with hexagonal flakes of NCA-L@BG, where the NF was decorated with a large number of LTH hybridized with BG flakes both outside and inside, and the porous structure of NF was retained even after the hydrothermal growth. This hierarchical array could be expected to improve the capacitive performance of the electrode by enabling an easy access of ions and high ionic mobility without any blocks from binders at the electrode/electrolyte interface. ${ }^{29}$ TEM analysis was performed to further examine the detailed morphology of the NCA-L powder and the NCA-L@BG-NF-3. From Fig. 3a and $\mathrm{b}$, one can observe the thin hexagonal nanoflakes with diameters from 39.5 to $69.5 \mathrm{~nm}$ and lengths from 83 to $141 \mathrm{~nm}$ in NCA-L powder. The hexagonal nanoflakes are very indistinct, but can be seen as an homogeneous contrast, reflecting their thin nature and uniform thickness. ${ }^{30}$ Fig. $3 \mathrm{c}$ and d, related to NCA-L@BG-NF-3, show BG sheets distributed on the surface of hexagonal NCA-L flakes. The face-to-face assembly of BG and NCA-L improves their contact area, which is beneficial for efficient electron transport between the active material and NF. It was also observed that the NCA-L flakes were intimately interacting with the functionalized graphene sheets and most of them were parallel to the graphene sheets. ${ }^{31}$ Both the BG sheets and NCA-L flacks could be clearly observed in NCA-L@BG-NF-3, which showed a significantly different assembly of NCA-L sheets from hexagonal structures to graphene-supported LTH sheets as reported earlier. This is attributed to the anchoring effect of the polar surfaces of the BG sheets on the NCA-L sheets due to the electrostatic interactions between them. ${ }^{32}$ Moreover, the high-resolution TEM (HRTEM) image (Fig. 3e) of the NCA-
L@BG-NF-3 hybrid further confirms that the structure is crystalline, with alternating clear lattice fringes contributing to the thickness of $0.75 \mathrm{~nm},{ }^{33}$ which corresponds to the $d_{003}$ value of rhombohedral NCA-LTH in accordance with the XRD results. ${ }^{34}$ Furthermore, the selected area of NCA-L@BG-NF-3 used for the SEM EDS elemental mapping confirmed the uniform distribution of Ni, Co, Al, Br, and C (Fig. 4a). Fig. 4b depicts the EDS spectrum analysis, where the atomic percentage of the individual components were calculated and the results confirmed the presence of Ni, Co, Al, Br, and C in NCA-L@BG-NF-3.35

$\mathrm{X}$-ray diffraction (XRD) analysis provides information on the crystallinity of materials. Fig. 5a illustrates the XRD patterns of the NCA-L@BG-3 powder, NCA-L@BG-NF-3, NCA-L@G-NF, and NCA-L-NF samples. The diffraction patterns of all samples correspond well with the standard compound $\mathrm{Co}_{6} \mathrm{Al}_{2} \mathrm{CO}_{3}(\mathrm{OH})$. $16 \mathrm{H}_{2} \mathrm{O}$ (JCPDS: 51-0045), with the well-defined diffraction peaks indexed to a series of (003), (006), (012), (015), (018), (110), and (113) planes. ${ }^{36}$ Moreover, some of the diffraction peaks could also be indexed to a distinctive rhombohedral phase Ni-Al hydrotalcite (JCPDS No. 15-0087). ${ }^{30}$ The sharp diffraction peaks of powder scratched from NCA-L@BG-NF-3 revealed that the crystal grew along a certain axis with high crystallinity and an excellent layered feature with an interlayer distance of $0.75 \mathrm{~nm}$ $\left(d_{003}\right)$, indicating the occupancy of $\mathrm{CO}_{3}{ }^{2-}$ ions and water molecules in the interlayer spaces. ${ }^{34}$ No typical diffraction peaks of BG or graphene were observed in NCA-L@BG-3 powder, NCAL@BG-NF-3, or NCA-L@G-NF hybrid, indicating that the integration of BG nanosheets does not significantly affect the crystal structure of NCA-LTH. ${ }^{37}$ In addition, the functionalized

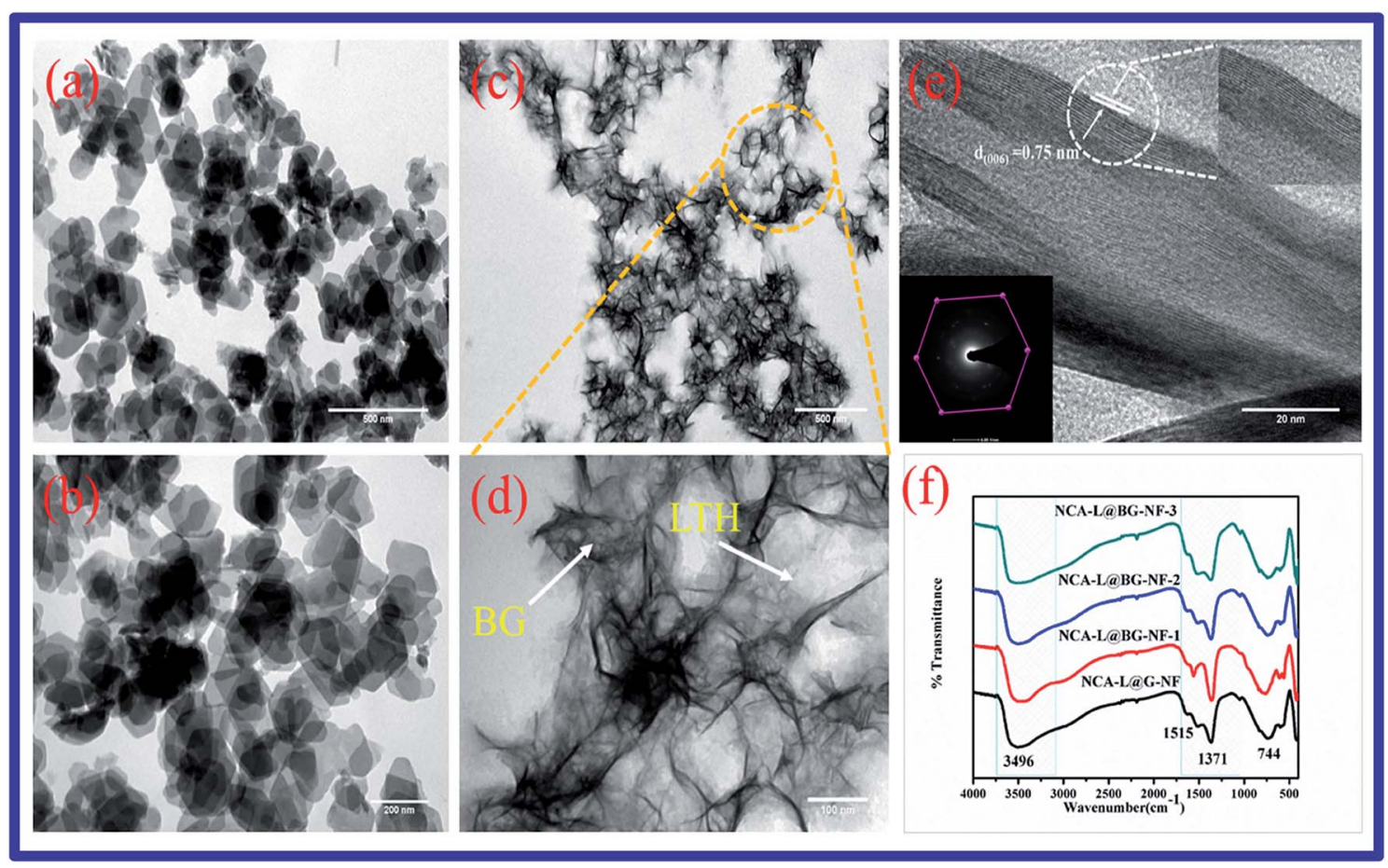

Fig. 3 (a, b) Low- and high-resolution TEM images of NCA-L powder showing a hexagonal-like morphology; (c, d) NCA-L@BG-NF-3; (e) HRTEM image of NCA-L@BG-NF-3, (the inset is the SAED pattern); (f) FTIR spectra of NCA-L-@G-NF, NCA-L@BG-NF-1, NCA-L@BG-NF-2, NCA-L@BGNF-3. 


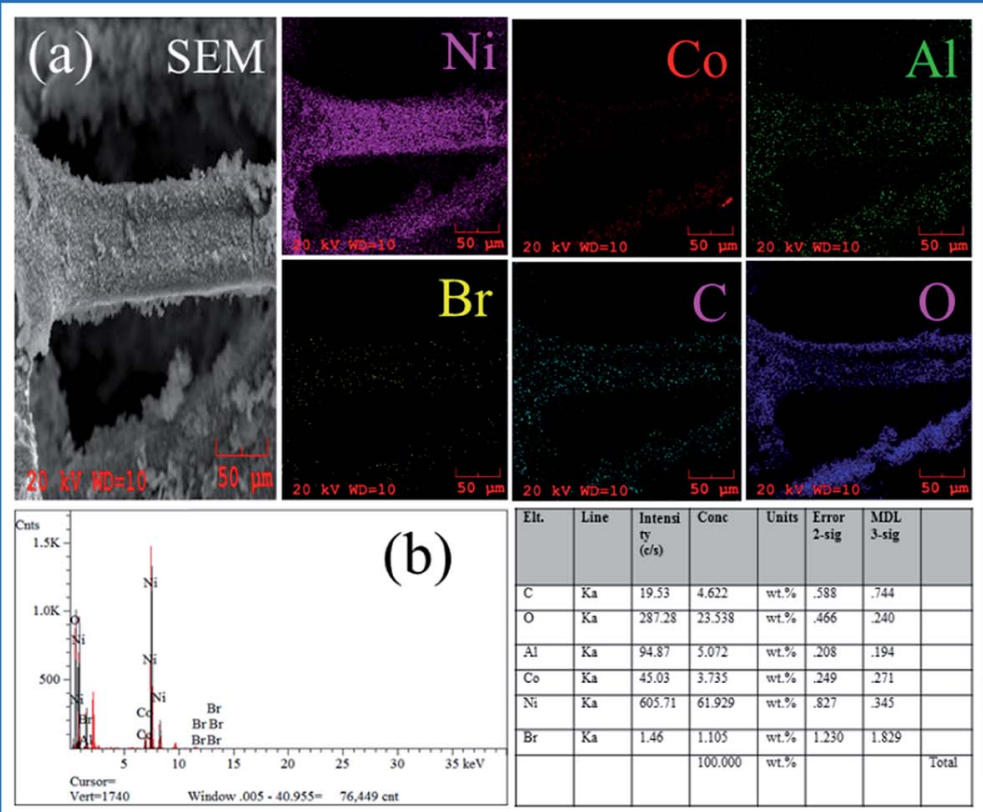

\section{(c)}

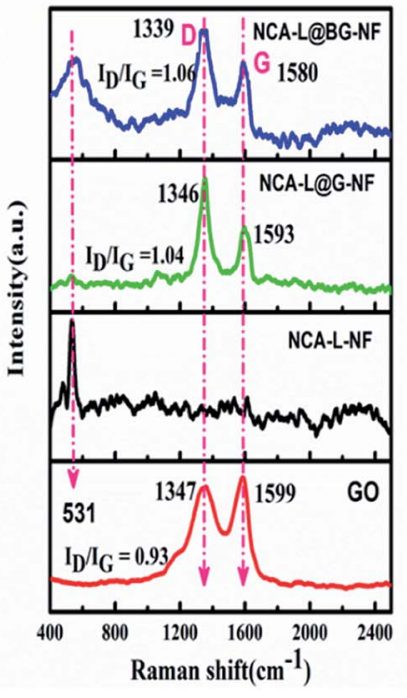

Fig. 4 (a) SEM EDS mappings (Ni, Co, Al, C, and Br) and (b) EDS spectrum for NCA-L@BG-NF-3; (c) Raman spectra of GO, NCA-L-NF, NCA-L@GNF, and NCA-L@BG-NF-3.

graphene layers are highly discrete in the hydrotalcite structure, and a small amount of $\mathrm{C}$ inserted into the LTHs does not hamper the growth of LTH crystals. ${ }^{38}$ Moreover, the weak peaks of the rest of the samples grown on $\mathrm{NF}$ at 11.6, 23.3, and 34.2 were complimented with the peaks of the NCA-L@BG-3 powder, demonstrating that the samples were successfully grown on $\mathrm{Ni}$ foam. In addition, three strong peaks (denoted by "\$" in Fig. 5a) located at $44.5^{\circ}, 52.1^{\circ}$, and $76.42^{\circ}$ for all samples were indexed to metal Ni (PCPDF 04-0850) from the NF substrate. ${ }^{39}$

The surface chemical composition of the samples scratched from the NCA@G-L-NF, NCA-L@BG-NF-1, NCA-L@BG-NF-2, and NCA-L@BG-NF-3 samples were analyzed by FT-IR spectroscopy, with the spectra shown in Fig. 3f. The spectra of all samples exhibit a broad absorption band at around 3466 and $3434 \mathrm{~cm}^{-1}$, originating from the stretching vibration of $\mathrm{OH}^{-}$ groups of the metal hydroxide layer and interlayer water, and from hydrogen bonding among the hydroxyl groups in all the LTH samples. The weak band at $1625 \mathrm{~cm}^{-1}$ is due to the bending mode of water molecules. ${ }^{40}$ The characteristic peaks at 1369 and $781 \mathrm{~cm}^{-1}$ are attributed to the $\nu_{3}$ vibration and bending modes of the interlayer anion $\left(\mathrm{CO}_{3}{ }^{2-}\right)$, respectively, which was released from urea hydrolysis during the hydrothermal procedure. ${ }^{\mathbf{4 1 , 4 2}}$ The above analysis demonstrated that the water molecules and carbonate ions had been successfully intercalated into the interlayer space of NCA-L during the assembly process. For all the LTH samples, the bands recorded below $800 \mathrm{~cm}^{-1}$ could be accounted for from the lattice vibration modes for $\mathrm{M}-\mathrm{O}(\mathrm{Ni}, \mathrm{Co}, \mathrm{Al}-\mathrm{O}) .{ }^{9}$ In comparison with $\mathrm{GO}(\mathrm{S} 2)$, most of the peak intensities corresponding to carbonyl, epoxide, and ether groups have disappeared or weakened in the FT-IR spectrum of NCA-L@G-NF and NCA-L@BG-NF-3, signifying that NCA-L was successfully combined with GO or BG in the as-prepared hybrid electrode. ${ }^{43}$

Raman spectroscopy is a non-destructive technique, which is widely used to characterize the graphitization of materials. The Raman scattering spectra of the GO, NCA-L-NF, NCA-L@G-NF, and NCA-L@BG-NF-3 samples were recorded and are shown in Fig. 4c. For graphitic materials, there are usually two feature peaks known as the D band and $\mathrm{G}$ band. The D band (usually observed at 1300-1400 $\mathrm{cm}^{-1}$ ) arises from a breathing mode of point photons of $\mathrm{A}_{1 \mathrm{~g}}$ symmetry; the presence of the $\mathrm{D}$ band indicates defects in the graphene layer. The $\mathrm{G}$ band (in the region of 1500-1600 $\mathrm{cm}^{-1}$ ) arises from the first order scattering of the $\mathrm{E}_{2 \mathrm{~g}}$ phonon at the Brillouin zone center, resulting from the bond stretching of $\mathrm{sp}^{2}$ carbon lattice pairs in both rings and chains. $^{44,45}$ A strong peak located at $531 \mathrm{~cm}^{-1}$ is typically assigned to NCA-LTH. ${ }^{9}$ It is known that the integrated intensity ratio of the bands $\left(I_{\mathrm{D}} / I_{\mathrm{G}}\right)$ is used to qualitatively analyze the structural defects and disorder of graphite materials. Thus, it was found that GO has an $I_{\mathrm{D}} / I_{\mathrm{G}}$ ratio of 0.93 and then, its values gradually increase from NCA-L@G-NF (1.04) to NCA-L@BG-NF3 (1.06). This is related to the defect density within the graphene structure and to the concentration of $\mathrm{sp}^{3}$ hybridized carbon atoms, which evidently indicates the intimate contact of LTH with BG and graphene species, suggesting the increased structural defects in all the prepared samples. ${ }^{46}$ Comparative studies of the Raman spectra (Fig. 4c) show that the G band of NCAL@BG-NF-3 shifts to lower frequency (compared with that of GO). This deviation $\left(\sim 19 \mathrm{~cm}^{-1}\right)$ in the $\mathrm{G}$ band can be attributed to recovery of the conjugated structure of the carbon atoms, which resonate at lower frequencies. In addition, these shifts in the Raman peaks could be attributed to the formation of 


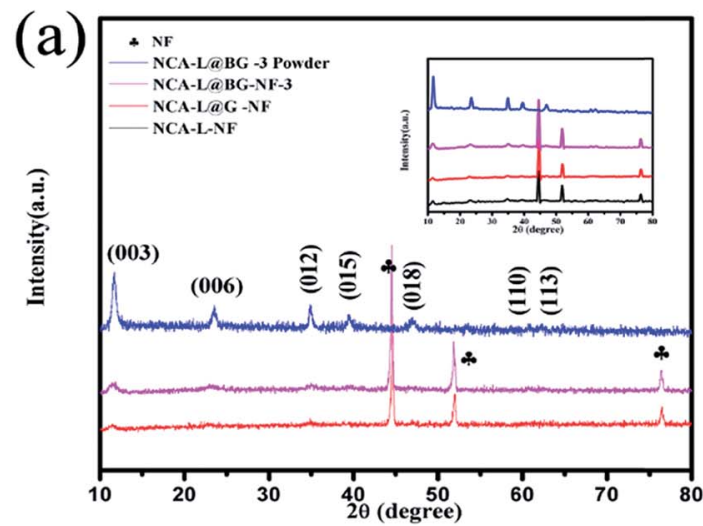

(c)

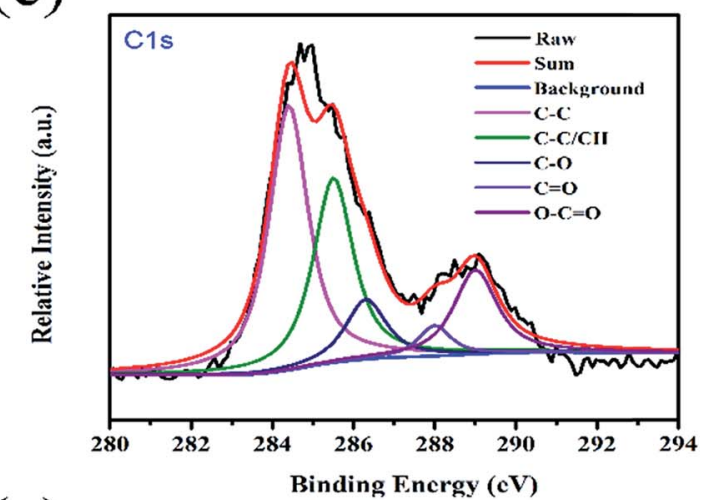

(e)

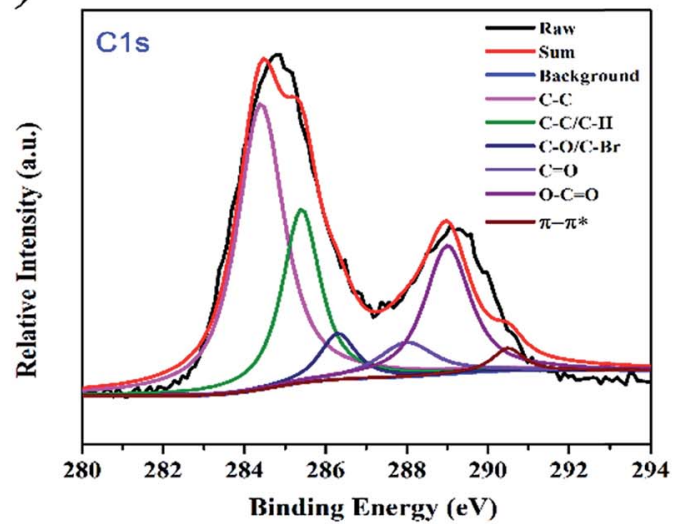

(b)

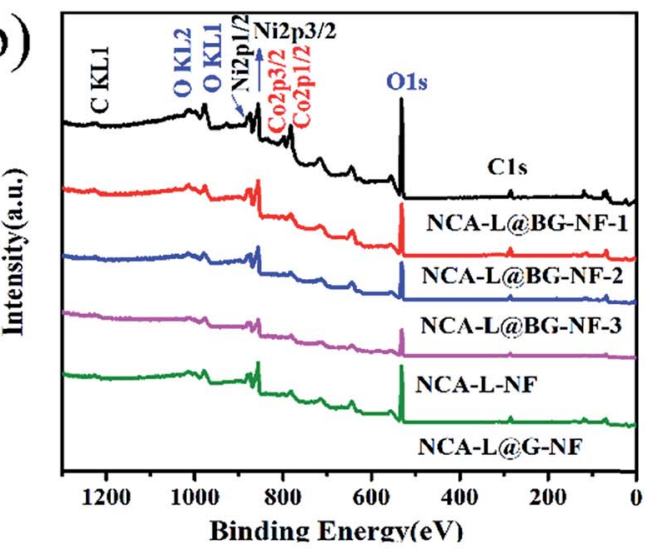

(d)

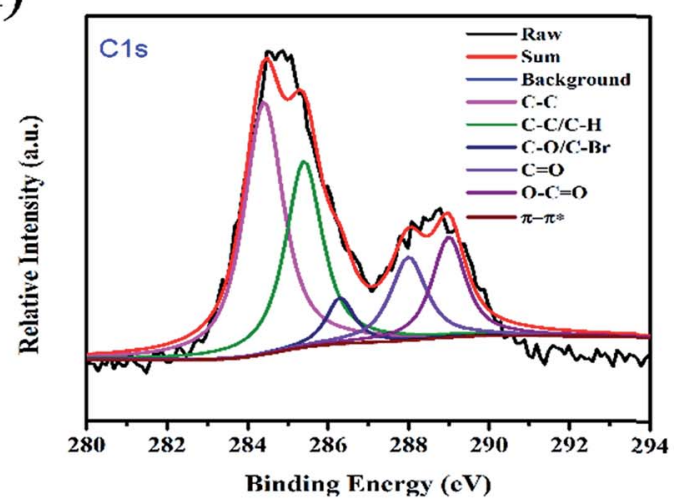

(f)

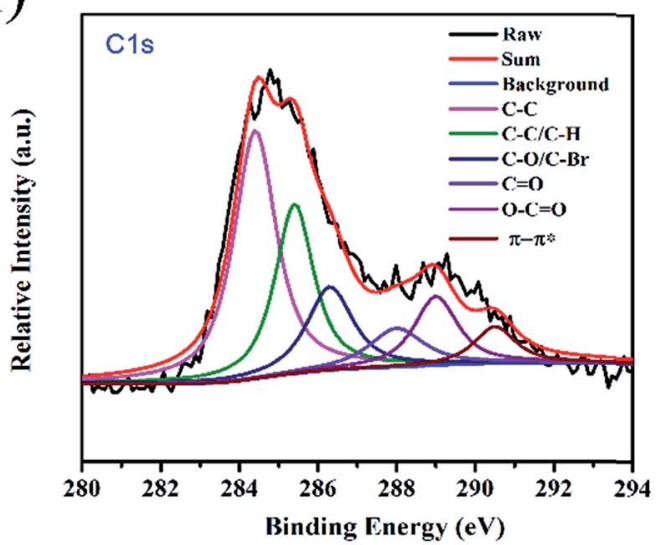

Fig. 5 (a) XRD patterns of NCA-L(aBG-3 powder, NCA-L(aBG-NF-3, NCA-L(aG-NF, NCA-L-NF; (b) XPS survey spectra of the samples (c); C 1s XPS spectra of NCA-L@G-NF (d), NCA-L@BG-NF-1 (e), NCA-L@BG-NF-2; and (f) NCA-L@BG-NF-3.

abundant $\mathrm{sp}^{3} \mathrm{C}-\mathrm{H}$ bonds. The dense ripples also contribute in confirming the bromination of graphene in the NCA-L@BG-NF3 sample. $^{13}$

XPS analysis was used to determine the accurate composition, chemical bonds, and oxidation states of the elements in the NCA-L-NF, NCA-L@GN-NF, and NCA-L@BGN-NF with three different feeding mole ratios. As shown in Fig. 5b-f, the survey spectra of all the prepared samples present characteristic peaks of C 1s, O 1s, Ni 2p, Co 2p, and Al 2p, confirming the presence of $\mathrm{C}, \mathrm{O}, \mathrm{Ni}, \mathrm{Co}$, and $\mathrm{Al}$. Furthermore, $\mathrm{Br} 3 \mathrm{~d}$ peaks were also observed in the spectra of the NCA-L@BG-NF with three different feeding mole ratios, proving that the bromination along with LTH formation had successfully proceeded during the hydrothermal process. In Fig. 5b-f, the high-resolution $\mathrm{C} 1 \mathrm{~s}$ spectra of the samples were fitted and divided into six peaks, corresponding to different oxygen-containing functional groups that are referred here as six types of carbon bonds: $\mathrm{C}-\mathrm{C}(284.8$ $\mathrm{eV}), \mathrm{C}-\mathrm{C} / \mathrm{C}-\mathrm{H}(285.28 \mathrm{eV}), \mathrm{C}-\mathrm{O} / \mathrm{C}-\mathrm{Br}(286.88 \mathrm{eV}), \mathrm{C}=\mathrm{O}(288.78$ $\mathrm{eV}), \mathrm{O}-\mathrm{C}=\mathrm{O}(289.0 \mathrm{eV})$, and $\pi-\pi^{*}$ interaction $(290.5 \mathrm{eV}) .{ }^{47,48}$ The effect of bromination on the electronic structure of graphene was checked by comparing the XPS C 1s spectra of the NCAL@G-NF with all the brominated samples as shown in Fig. 3ce. Furthermore, the presence of the $\pi \rightarrow \pi^{*}$ shake-up, which is characteristic in materials such as graphene with delocalized p- 
electron systems, causes further overcrowding in the C (1s) region. The decline of a feature around $291 \mathrm{eV}$, corresponding to the $\pi \rightarrow \pi^{*}$ shake-up transition, can be attributed to partial disruption of the $\pi$ electrons or bromination of the system. ${ }^{\mathbf{4 9 , 5 0}}$ Furthermore, the $\mathrm{C}-\mathrm{O}$ and $\mathrm{C}-\mathrm{Br}$ bonds have very similar binding energies, whereby $\mathrm{C}-\mathrm{O}$ has been reported to be located at $286.6 \mathrm{eV}$ and $\mathrm{C}-\mathrm{Br}$ at $286.2 \mathrm{eV} \cdot{ }^{\mathbf{1 4}} \mathrm{A}$ detailed high-resolution peak fitting analysis of the $\mathrm{Ni}, \mathrm{Co}, \mathrm{Al}$, and $\mathrm{Br}$ spectra for all the prepared samples are shown in Fig. S3. $\uparrow$ The quantitative elemental composition of the samples obtained from the XPS analysis can be seen in Table $\mathrm{S} 1 . \dagger$ The relative atomic amounts of $\mathrm{C}$ increased in the order of NCA-L@G-NF < NCA-L@BG-NF-1 < NCA-L@BG-NF-2 < NCA-L@BG-NF-3. While the relative atomic amounts of $\mathrm{O}$ decreased in the order of NCA-L@G-NF > NCAL@BG-NF-1 > NCA-L@BG-NF-2 > NCA-L@BG-NF-3. This may be due to the reason that part of the oxygen-containing functional groups on the GO surface were removed or had bonded with $\mathrm{Br}$ atoms in the hydrothermal reaction, leading to the reduction of active sites for the adsorption of bivalent and trivalent cations.

\subsection{Electrochemical performance}

The electrochemical behavior of the highly open framework of the as-synthesized hybrid electrodes NCA-L-@NF, NCA-L@GNF, and NCA-L@BG-NF with three different feeding mole ratios were investigated by cyclic voltammetry (CV), galvanostatic charge-discharge, and electrochemical impedance (EIS) measurements in $6 \mathrm{M} \mathrm{KOH}$ aqueous electrolyte. Fig. 6 (a) shows the CV curves of NCA-L-@NF, NCA-L@G-NF, and NCA-L@BG$\mathrm{NF}$ with three different feeding mole ratios recorded at scan rates of $5 \mathrm{mV} \mathrm{s}^{-1}$. A couple of anodic/cathodic redox peaks can be seen in the $\mathrm{CV}$ curves of each sample, indicating that the faradic redox reaction related to $\mathrm{Ni}^{2+} / \mathrm{Ni}^{3+}$ and $\mathrm{Co}^{2+} / \mathrm{Co}^{3+}$ with the aid of $\mathrm{OH}^{-}$are involved during the charge-discharge process contributing to the pseudocapacitance. ${ }^{\mathbf{1 1}}$ The redox reaction can be represented as follows:

$$
\begin{aligned}
& \mathrm{LTH} \mathrm{Ni}^{2+}+\mathrm{OH}_{\mathrm{sol}}^{-} \Leftrightarrow \operatorname{LTH}\left(\mathrm{OH}^{-}\right) \mathrm{Ni}^{3+}+\mathrm{e}^{-} \\
& \mathrm{LTH} \mathrm{Co}^{2+}+\mathrm{OH}_{\mathrm{sol}}^{-} \Leftrightarrow \operatorname{LTH}\left(\mathrm{OH}^{-}\right) \mathrm{Co}^{3+}+\mathrm{e}^{-}
\end{aligned}
$$

In addition, the asymmetrical behavior in the cathodic peaks of the NCA-L-@NF, NCA-L@G-NF, NCA-L@BG-NF-1, NCAL@BG-NF-2, and NCA-L-NF-3 samples show kinetic irreversibility in the faradaic process. This might be assigned to resistance polarization in the region of ion diffusion in the porous electrode during the redox reactions. ${ }^{15,52}$ Furthermore, the integral area of the $\mathrm{CV}$ curves are significantly increased in the order of NCA-L@BG-NF-3 > NCA-L@BG-NF-1 > NCA-L-NF > NCA-L@BG-NF-2 > NCA-L@G-NF, suggesting that the NCAL@BG-NF-3 has a much higher average specific capacitance. In Fig. $6 \mathrm{~b}$, the galvanostatic charge/discharge measurements of the as-prepared electrodes in the potential range of 0-0.5 at a very high current density of $6 \mathrm{~A} \mathrm{~g}^{-1}$ are illustrated. As can be seen from the curves of all the prepared hybrids, the charge/ discharge curves were non-linear, which further confirms that the redox reaction occurs during the process. ${ }^{18,53}$ The longest discharge time of NCA-L@BG-NF-3 suggested that this composite electrode had the best charge-storage performance. At a current density of $6 \mathrm{~A} \mathrm{~g}^{-1}$, the specific capacities were calculated to be $1998 \mathrm{C} \mathrm{g}^{-1}$ for NCA-L@BG-NF-3, $1992 \mathrm{C} \mathrm{g}^{-1}$ for NCA-L@BG-NF-1, $1890 \mathrm{C} \mathrm{g}^{-1}$ for NCA-L-NF, $1770 \mathrm{C} \mathrm{g}^{-1}$ for NCAL@BG-NF-2, and $1554 \mathrm{C} \mathrm{g}^{-1}$ for NCA-L@G-NF as illustrated in Fig. 6c. The results suggest that the NCA-L@BG-NF-3 electrode exhibited superior specific capacity in the highly concentrated $6 \mathrm{M} \mathrm{KOH}$, indicating its enhanced charge-storage performance. ${ }^{54,55}$ In addition, with increase in concentration, the ionic conductivity of the electrolyte increased, which not only facilitated a high charge transfer, but also decreased the diffusion resistance, resulting in enhanced electrochemical performance. ${ }^{56}$ This could be attributed to the synergetic effect between conductive BG and NCA-L-NF when compared with pure NCA-L-NF. ${ }^{9}$ Because of the presence of numerous nanochannels, the graphene and BG in the electrode convey a conductive network for electron transportation. Also the unique morphology of NCA-L@BG-NF-3 acts as a perfect reservoir to facilitate enhanced contact and diffusion as well as the penetration of $\mathrm{OH}^{-}$ions for the highest redox processes for charge storage. ${ }^{57}$ The CV curves of the NCA-L@BG-NF-3 electrode at various scan rates of $6,10,20,40$, and $50 \mathrm{mV} \mathrm{s}^{-1}$ are shown in Fig. 6d, where it can be seen that with the increase in scan rate, the anodic peak is shifted toward lower and higher potential due to polarization. ${ }^{58}$ Each curve at the different scan rates represented redox couples, which shows that continuous faradic redox reactions of NCA-L are involved during the charge and discharge processes contributing to the total capacitance. ${ }^{59}$ Furthermore, even at a high scan rate of $50 \mathrm{mV} \mathrm{s}^{-1}$ the shape of the redox peaks was not influenced considerably, signifying enhanced mass transportation of ions and an excellent rate capability of the electrode. ${ }^{60}$ The same result could also be obtained from the nonlinear charge-discharge curves as shown in Fig. 6e. Fig. 6f shows the specific capacitances of NCA-L-NF, NCA@G-L-NF, NCA-L@BG-NF-1, NCA-L@BG-NF-2, and NCAL@BG-NF-3 at various current densities of 6, 8, 10, 15, and $20 \mathrm{~A} \mathrm{~g}^{-1}$. Here, NCA-L@BG-NF-3 revealed a clearly stable and higher specific capacity than that of NCA-L-NF, NCA@G-L-NF, NCA-L@BG-NF-1, and NCA-L@BG-NF-2 at all current densities. The specific capacities of NCA-L@BG-NF-3 was 1998, 1960, 1910, 1920, and $1600 \mathrm{C} \mathrm{g}^{-1}$ at 6, 8, 10, 15, and $20 \mathrm{~A} \mathrm{~g}^{-1}$, respectively, with a retention rate of $80.0 \%$, while those of NCAL-NF at $6,8,10,15$, and $20 \mathrm{~A} \mathrm{~g}^{-1}$ was $1554,1496,1470,1335$, and $1220 \mathrm{C} \mathrm{g}^{-1}$, respectively, with a retention rate of $78.5 \%$. Thus, the rate capability of NCA-L@BG-NF-3 was remarkably enhanced compared with NCA-L-NF. The noteworthy increase in their electrochemical activity is due to the bromination of $\mathrm{GO}$, which leads to the reduction. It is well-known that the use of BG is exceptionally strategic to serve as a good electronic conductor for the redox reactions to promote pseudocapacitance. Thus, the differences in the specific capacities of the NCA-L@BG-NF hybrids may originate from the hybridization of the brominated carbon alignment and bromine content in the electrodes. ${ }^{61}$ 

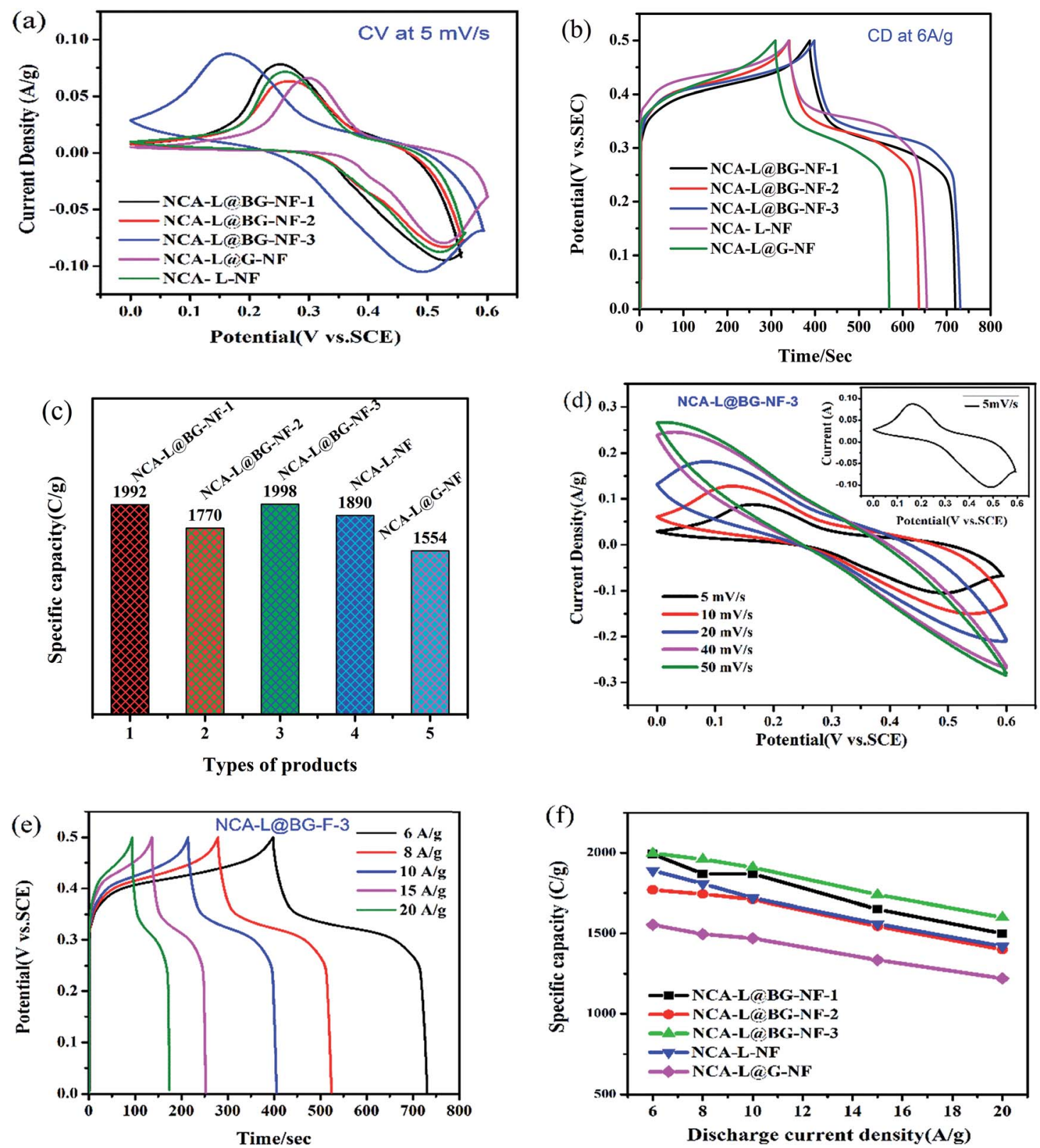

Fig. 6 (a) CV curves of NCA-L-NF and the composites at a scan rate of $5 \mathrm{mV} \mathrm{s}^{-1}$; (b) galvanostatic charge-discharge curves at a current density of $6 \mathrm{~A} \mathrm{~g}^{-1}$ respectively; (c) histogram of the specific capacity of the samples at $6 \mathrm{~A} \mathrm{~g}^{-1}$ (d) CV curves of NCA-L(aBG-NF-3 at various scan rates of 5 , 10, 20,40, and $50 \mathrm{mV} \mathrm{s}^{-1}$; (e) galvanostatic charge-discharge curves of NCA-LaBG-NF-3 at current densities of 6, 8, 10, 15, and 20 A g ${ }^{-1}$; (f) specific capacity of the samples at current densities of $6,8,10,15$, and $20 \mathrm{~A} \mathrm{~g}^{-1}$.

The transport characteristics of the charge carriers within the hybrid electrodes were probed by electrochemical impedance spectroscopy. Fig. 7 outlines the Nyquist plots of the sample electrodes, presenting an incomplete depressed semicircle in the high-frequency range and a non-straight line in the low-frequency region. This phenomenon could be ascribed to the result of the frequency dependence of ion diffusion to the electrode interface..$^{62}$ The charge-transfer resistance $\left(R_{\mathrm{CT}}\right)$ was calculated to be $0.366 \Omega$ for NCA-L@BG-NF-1, $0.952 \Omega$ for NCAL@BG-NF-2, $0.108 \Omega$ for NCA-L@BG-NF-3, and $0.468 \Omega$ for NCAL-NF, and $1.303 \Omega$ for NCA-L@G-NF, which suggests that $R_{\mathrm{CT}}$ decreased in the order of NCA-L@BG-NF-3 > NCA-L@BG-NF-1 >
NCA-L-NF > NCA-L@BG-NF-2 > NCA-L@G-NF. The results obtained demonstrate that NCA-L@BG-NF-3 had the lowest $R_{\mathrm{CT}}$, the highest capacitive performance, the lowest diffusive resistance of ions, and the fastest electron transport at the electrode/ electrolyte interface. The overall IES findings suggested that NCA-L@BG-NF-3 possessed evidently enhanced electrochemical properties, suggesting its potential to be used as an electrode for supercapacitors. ${ }^{62,63}$

For supercapacitor applications, apart from the high specific capacity, the long-term cycling stability of the electrodes is also an important requirement. Fig. 8 illustrates the cycling performance of the fabricated NCA-L@BG-NF-3. On the contrary, the 


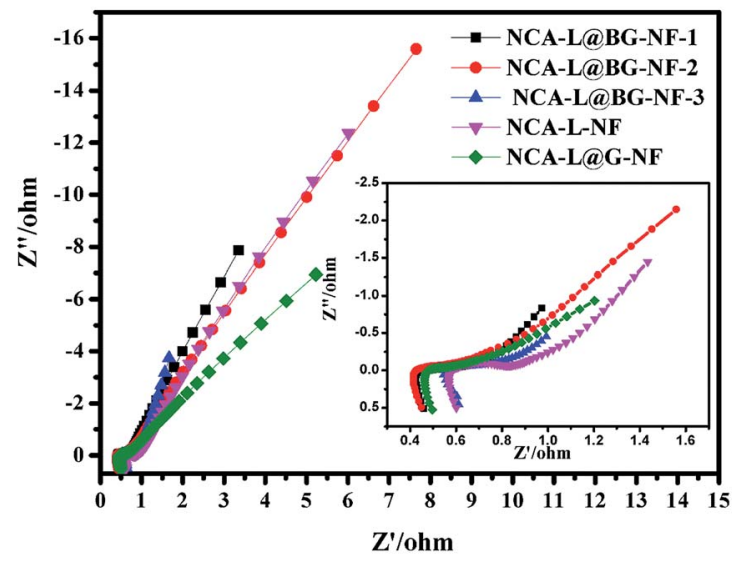

Fig. 7 Nyquist plots of the EIS data for the sample electrodes.

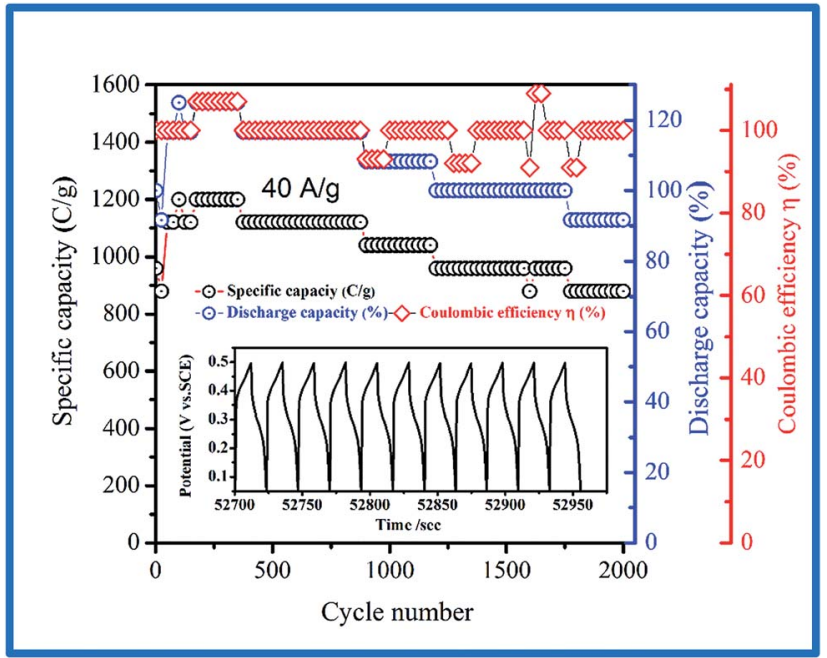

Fig. 8 Specific capacity and coulombic efficiency $(\eta)$ of (a) NCA-La BG-NF-3, hybrid electrode as a function of cycle number (inset shows the last few charge-discharge cycles).

NCA-L@G-NF and NCA-L-NF electrodes were evaluated over 2000 galvanostatic charge-discharge cycles at a very high current density of $40 \mathrm{~A} \mathrm{~g}^{-1}$ and the results obtained are shown in Fig. S4. $\dagger$ After 2000 cycles, the NCA-L@BG-NF-3, NCA-L@GNF, and NCA-L-NF samples retained 90.1\%, $85.7 \%$, and $64.7 \%$, of their initial specific capacities, respectively. Thus, NCA-L@BG-NF-3 exhibited clearly the best capacitance retention compared to the other two hybrid electrodes, which might be attributed to the high efficiency electron and electrolyte transportation of BG. ${ }^{64}$

\section{Conclusion}

From the outcome of our investigations, it is possible to conclude that a triple hydroxide hybrid based on $\mathrm{Ni} / \mathrm{Co} / \mathrm{Al}$ and BG was grown directly on Ni foam through a facile one-step in situ crystallization hydrothermal method, achieving superior electrochemical properties as a supercapacitor electrode. Because of the well-defined hierarchical morphology, high active surface area, and synergistic contributions of the individual components, the NCA-L@BG-NF-3 hybrid demonstrated excellent electrochemical performances as an electrode material, exhibiting a maximum specific capacity of $1998 \mathrm{C} \mathrm{g}^{-1}$ at $6 \mathrm{~A} \mathrm{~g}^{-1}$, excellent rate capability of $75.3 \%$ at $20 \mathrm{~A} \mathrm{~g}^{-1}$, and excellent cyclic stability of $\sim 91 \%$ capacitance retention after 2000 cycles at $20 \mathrm{~A} \mathrm{~g}^{-1}$, with $100 \%$ coulombic efficiency, which were significantly higher than those previously reported for LDH composites. In addition, the material demonstrated good long-term cyclic stability and a low $R_{\mathrm{CT}}$. Furthermore, the NCAL@BG directly grown on the Ni foam had greatly improved electrochemical capabilities. These results suggest that the asprepared NCA-L@BG-NF- 3 hybrid could be a superior candidate for the fabrication of binder-free electrodes. It is also suggested that the proposed synthetic strategy can be extended to the fabrication of other triple hydroxide binder-free electrodes for supercapacitor applications.

\section{Conflicts of interest}

The authors declare no competing financial interest.

\section{Acknowledgements}

The authors would like to gratefully acknowledge the support of this study by the National Natural Science Foundation of China (No. 21501104) the Natural Science foundation of Heilongjiang Province (B2015014).

\section{References}

1 J.-H. Kim, J.-H. Kim, K.-H. Choi, H. K. Yu, J. H. Kim, J. S. Lee and S.-Y. Lee, Inverse Opal-Inspired, Nanoscaffold Battery Separators: A New Membrane Opportunity for HighPerformance Energy Storage Systems, Nano Lett., 2014, 14, 4438-4448.

2 Q. Van Overmeere, K. Kerman and S. Ramanathan, Energy Storage in Ultrathin Solid Oxide Fuel Cells, Nano Lett., 2012, 12, 3756-3760.

3 L.-F. Chen, X.-D. Zhang, H.-W. Liang, M. Kong, Q.-F. Guan, P. Chen, Z.-Y. Wu and S.-H. Yu, Synthesis of NitrogenDoped Porous Carbon Nanofibers as an Efficient Electrode Material for Supercapacitors, ACS Nano, 2012, 6, 7092-7102.

$4 \mathrm{H}$. Yin and Z. Tang, Ultrathin two-dimensional layered metal hydroxides: an emerging platform for advanced catalysis, energy conversion and storage, Chem. Soc. Rev., 2016, 45, 4873-4891.

5 X. Sun and S. K. Dey, Insights Into the Synthesis of Layered Double Hydroxide (LDH) Nanoparticles: Part 2. Formation Mechanisms of LDH, J. Colloid Interface Sci., 2015, 458, 160-168.

6 Y. Wimalasiri, R. Fan, X. S. Zhao and L. Zou, Assembly of NiAl layered double hydroxide and graphene electrodes for supercapacitors, Electrochim. Acta, 2014, 134, 127-135. 
7 Y. Han, Z.-H. Liu, Z. Yang, Z. Wang, X. Tang, T. Wang, L. Fan and $\mathrm{K}$. Ooi, Preparation of $\mathrm{Ni}^{2+}-\mathrm{Fe}^{3+}$ Layered Double Hydroxide Material with High Crystallinity and WellDefined Hexagonal Shapes, Chem. Mater., 2008, 20, 360-363.

8 M. Li, J. P. Cheng, J. Wang, F. Liu and X. B. Zhang, The growth of nickel-manganese and cobalt-manganese layered double hydroxides on reduced graphene oxide for supercapacitor, Electrochim. Acta, 2016, 206, 108-115.

9 J. Fang, M. Li, Q. Li, W. Zhang, Q. Shou, F. Liu, X. Zhang and J. Cheng, Microwave-assisted synthesis of CoAl-layered double hydroxide/graphene oxide composite and its application in supercapacitors, Electrochim. Acta, 2012, 85, 248-255.

10 S. Deng, H. Wang, H. Liu, J. Liu and H. Yan, Research Progress in Improving the Rate Performance of $\mathrm{LiFePO}_{4}$ Cathode Materials, Nano-Micro Lett., 2014, 6, 209-226.

11 S. Huang, G. N. Zhu, C. Zhang, W. W. Tjiu, Y. Y. Xia and T. Liu, Immobilization of Co-Al layered double hydroxides on graphene oxide nanosheets: growth mechanism and supercapacitor studies, ACS Appl. Mater. Interfaces, 2012, 4, 2242-2249.

12 S. Saha, M. Jana, P. Samanta, N. C. Murmu and T. Kuila, Efficient Access of Voltammetric Charge in Hybrid Supercapacitor Configured with Potassium Incorporated Nanographitic Structure Derived from Cotton (Gossypium arboreum) as Negative and $\mathrm{Ni}(\mathrm{OH})_{2} / \mathrm{rGO}$ Composite as Positive Electrode, Ind. Eng. Chem. Res., 2016, 55, 1107411084.

13 Y. Li, H. Chen, L. Y. Voo, J. Ji, G. Zhang, G. Zhang, F. Zhang and X. Fan, Synthesis of partially hydrogenated graphene and brominated graphene, J. Mater. Chem., 2012, 22, 15021.

14 P. Šimek, K. Klímová, D. Sedmidubský, O. Jankovský, M. Pumera and Z. Sofer, Towards graphene iodide: iodination of graphite oxide, Nanoscale, 2015, 7, 261-270.

15 W. Peng, H. Li and S. Song, Synthesis of Fluorinated Graphene/CoAl-Layered Double Hydroxide Composites as Electrode Materials for Supercapacitors, ACS Appl. Mater. Interfaces, 2017, 9, 5204-5212.

16 S. Wu, K. S. Hui, K. N. Hui and K. H. Kim, ElectrostaticInduced Assembly of Graphene-Encapsulated Carbon@Nickel-Aluminum Layered Double Hydroxide Core-Shell Spheres Hybrid Structure for High-Energy and High-Power-Density Asymmetric Supercapacitor, ACS Appl. Mater. Interfaces, 2017, 9, 1395-1406.

17 N. Yulian, L. Ruiyi, L. Zaijun, F. Yinjun and L. Junkang, High-performance supercapacitors materials prepared via in situ growth of NiAl-layered double hydroxide nanoflakes on well-activated graphene nanosheets, Electrochim. Acta, 2013, 94, 360-366.

18 L. Zhang, X. Zhang, L. Shen, B. Gao, L. Hao, X. Lu, F. Zhang, B. Ding and C. Yuan, Enhanced high-current capacitive behavior of graphene/CoAl-layered double hydroxide composites as electrode material for supercapacitors, $J$. Power Sources, 2012, 199, 395-401.

19 L. Zhang, K. N. Hui, K. S. Hui, X. Chen, R. Chen and H. Lee, Role of graphene on hierarchical flower-like NiAl layered double hydroxide-nickel foam-graphene as binder-free electrode for high-rate hybrid supercapacitor, Int. J. Hydrogen Energy, 2016, 41, 9443-9453.

20 X. L. Guo, X. Y. Liu, X. D. Hao, S. J. Zhu, F. Dong, Z. Q. Wen and Y. X. Zhang, Nickel-Manganese Layered Double Hydroxide Nanosheets Supported on Nickel Foam for High-performance Supercapacitor Electrode Materials, Electrochim. Acta, 2016, 194, 179-186.

21 M. Jabeen, M. Ishaq, W. Song, L. Xu, I. Maqsood and Q. Deng, UV-Assisted Photocatalytic Synthesis of ZnOReduced Graphene Oxide Nanocomposites with Enhanced Photocatalytic Performance in Degradation of Methylene Blue, ECS J. Solid State Sci. Technol., 2017, 6, M36-M43.

22 B. Zhao, D. Chen, X. Xiong, B. Song, R. Hu, Q. Zhang, B. H. Rainwater, G. H. Waller, D. Zhen, Y. Ding, Y. Chen, C. Qu, D. Dang, C.-P. Wong and M. Liu, A high-energy, long cycle-life hybrid supercapacitor based on graphene composite electrodes, Energy Storage Materials, 2017, 7, 3239.

23 D. Momodu, A. Bello, J. Dangbegnon, F. Barzeger, F. Taghizadeh, M. Fabiane, A. T. C. Johnson and N. Manyala, Solvothermal synthesis of NiAl double hydroxide microspheres on a nickel foam-graphene as an electrode material for pseudo-capacitors, AIP Adv., 2014, 4, 97122.

24 S. K. Meher and G. R. Rao, Ultralayered $\mathrm{Co}_{3} \mathrm{O}_{4}$ for highperformance supercapacitor applications, J. Phys. Chem. C, 2011, 115, 15646-15654.

25 U. M. Patil, J. S. Sohn, S. B. Kulkarni, S. C. Lee, H. G. Park, K. V. Gurav, J. H. Kim and S. C. Jun, Enhanced supercapacitive performance of chemically grown cobaltnickel hydroxides on three-dimensional graphene foam electrodes, ACS Appl. Mater. Interfaces, 2014, 6, 2450-2458.

26 Y. Han, Z.-H. Liu, Z. Yang, Z. Wang, X. Tang, T. Wang, L. Fan and K. Ooi, ChemInform Abstract: Preparation of $\mathrm{Ni}^{2+}-\mathrm{Fe}^{3+}$ Layered Double Hydroxide Material with High Crystallinity and Well-Defined Hexagonal Shapes., J. Cheminf., 2008, 20, 360-363.

27 H. Chen, L. Hu, M. Chen, Y. Yan and L. Wu, Nickel-Cobalt Layered Double Hydroxide Nanosheets for Highperformance Supercapacitor Electrode Materials, $A d v$. Funct. Mater., 2014, 24, 934-942.

28 L. Zhang, K. N. Hui, K. S. Hui, X. Chen, R. Chen and H. Lee, Role of graphene on hierarchical flower-like NiAl layered double hydroxide-nickel foam-graphene as binder-free electrode for high-rate hybrid supercapacitor, Int. J. Hydrogen Energy, 2016, 41, 9443-9453.

29 S. Dai, B. Zhao, C. Qu, D. Chen, D. Dang, B. Song, B. M. deGlee, J. Fu, C. Hu, C.-P. Wong and M. Liu, Controlled synthesis of three-phase NixSy/rGO nanoflake electrodes for hybrid supercapacitors with high energy and power density, Nano Energy, 2017, 33, 522-531.

30 W. Yang, Z. Gao, J. Wang, J. Ma, M. Zhang and L. Liu, Solvothermal one-step synthesis of $\mathrm{Ni}-\mathrm{Al}$ layered double hydroxide/carbon nanotube/reduced graphene oxide sheet ternary nanocomposite with ultrahigh capacitance for supercapacitors, ACS Appl. Mater. Interfaces, 2013, 5, 54435454. 
31 J. Xu, S. Gai, F. He, N. Niu, P. Gao, Y. Chen and P. Yang, Reduced graphene oxide/ $\mathrm{Ni}_{1-\mathrm{x}} \mathrm{Co}_{x} \mathrm{Al}$-layered double hydroxide composites: preparation and high supercapacitor performance, Dalton Trans., 2014, 43, 11667.

32 J. Memon, J. Sun, D. Meng, W. Ouyang, M. A. Memon, Y. Huang, S. Yan and J. Geng, Synthesis of graphene/Ni-Al layered double hydroxide nanowires and their application as an electrode material for supercapacitors, J. Mater. Chem. A, 2014, 2, 5060-5067.

33 Q. Zhang, B. Zhao, J. Wang, C. Qu, H. Sun, K. Zhang and M. Liu, High-performance hybrid supercapacitors based on self-supported 3D ultrathin porous quaternary $\mathrm{Zn}-\mathrm{Ni}-\mathrm{Al}-$ Co oxide nanosheets, Nano Energy, 2016, 28, 475-485.

34 F. He, Z. Hu, K. Liu, H. Guo, S. Zhang, H. Liu and Q. Xie, Facile fabrication of GNS/NiCoAl-LDH composite as an advanced electrode material for high-performance supercapacitors, J. Solid State Electrochem., 2014, 19, 607617.

35 H. Chen, C.-K. Hsieh, Y. Yang, X. Y. Liu, C.-H. Lin, C.-H. Tsai, Z. Q. Wen, F. Dong and Y. X. Zhang, Hierarchical Nickel Cobaltate/Manganese Dioxide Core-Shell Nanowire Arrays on Graphene-Decorated Nickel Foam for High-Performance Supercapacitors, ChemElectroChem, 2017, 4, 2414-2422.

36 Y. Kim and S. Kim, Direct growth of cobalt aluminum double hydroxides on graphene nanosheets and the capacitive properties of the resulting composites, Electrochim. Acta, 2015, 163, 252-259.

37 G. Wang, Z. Wei, L. Sang, G. Chen, W. Zhang, X. Dong and M. Qi, Morphology, crystallization and mechanical properties of poly( $\varepsilon$-caprolactone)/graphene oxide nanocomposites, Chin. J. Polym. Sci., 2013, 31, 1148-1160.

38 J. Memon, J. Sun, D. Meng, W. Ouyang, M. A. Memon, Y. Huang, S. Yan and J. Geng, Synthesis of graphene/Ni-Al layered double hydroxide nanowires and their application as an electrode material for supercapacitors, J. Mater. Chem. A, 2014, 2, 5060-5067.

39 Y. Shao, Y. Zhao, H. Li and C. Xu, Three-Dimensional Hierarchical $\mathrm{Ni}_{x} \mathrm{Co}_{1_{-x}} \mathrm{O} / \mathrm{Ni}_{y} \mathrm{Co}_{2-y} \mathrm{P} @ \mathrm{C}$ Hybrids on Nickel Foam for Excellent Supercapacitors, ACS Appl. Mater. Interfaces, 2016, 8, 35368-35376.

40 F. He, Z. Hu, K. Liu, S. Zhang, H. Liu and S. Sang, In situ fabrication of nickel aluminum-layered double hydroxide nanosheets/hollow carbon nanofibers composite as a novel electrode material for supercapacitors, J. Power Sources, 2014, 267, 188-196.

41 J. Xu, S. Gai, F. He, N. Niu, P. Gao, Y. Chen and P. Yang, A sandwich-type three-dimensional layered double hydroxide nanosheet array/graphene composite: fabrication and high supercapacitor performance, J. Mater. Chem. A, 2014, 2, 1022-1031.

42 R. Xie, G. Fan, Q. Ma, L. Yang and F. Li, Facile synthesis and enhanced catalytic performance of graphene-supported $\mathrm{Ni}$ nanocatalyst from a layered double hydroxide-based composite precursor, J. Mater. Chem. A, 2014, 2, 7880.

43 F.-G. Zhao, G. Zhao, X.-H. Liu, C.-W. Ge, J.-T. Wang, B.-L. Li, Q.-G. Wang, W.-S. Li and Q.-Y. Chen, Fluorinated graphene: facile solution preparation and tailorable properties by fluorine-content tuning, J. Mater. Chem. A, 2014, 2, 8782.

44 K. K. Tadi, S. K. Bikkarolla, K. Bhorkar, S. Pal, N. Kunchur, Indulekha N, S. Radhakrishnan, R. K. Biroju and T. N. Narayanan, Defluorination of Fluorographene Oxide via Solvent Interactions, Part. Part. Syst. Charact., 2017, 34, 1600346.

45 S. N. Alam, N. Sharma and L. Kumar, Synthesis of Graphene Oxide (GO) by Modified Hummers Method and Its Thermal Reduction to Obtain Reduced Graphene Oxide (rGO), Graphene, 2017, 6, 1-18, Scientific Research Publishing.

46 A. O. Jankovsky, M. Lojka, J. Luxa, O. Tomanec, R. Zboril, Z. Sofer, M. Lojka, J. Luxa and D. Sedmidubský, Selective bromination of graphene oxide by Hunsdiecker reaction Selective bromination of graphene oxide by Hunsdiecker reaction, Chem.-Eur. J., 2017, 23, 10473-10479.

47 Z. Wang, J. Wang, Z. Li, P. Gong, X. Liu, L. Zhang, J. Ren, H. Wang and S. Yang, Synthesis of fluorinated graphene with tunable degree of fluorination, Carbon, 2012, 50, 5403-5410.

48 E. C. Vermisoglou, T. Giannakopoulou, G. Romanos, M. Giannouri, N. Boukos, C. Lei, C. Lekakou and C. Trapalis, Effect of hydrothermal reaction time and alkaline conditions on the electrochemical properties of reduced graphene oxide, Appl. Surf. Sci., 2015, 358, 100-109.

49 K. A. Wepasnick, B. A. Smith, K. E. Schrote, H. K. Wilson, S. R. Diegelmann and D. H. Fairbrother, Surface and structural characterization of multi-walled carbon nanotubes following different oxidative treatments, Carbon, 2010, 49, 24-36.

50 Y. V. Fedoseeva, A. Yaya and C. P. Ewels, Bromination of Double-Walled Carbon Nanotubes, Chem. Mater., 2012, 24, 2708-2715.

51 L. H. Su, X. G. Zhang and Y. Liu, Electrochemical performance of Co-Al layered double hydroxide nanosheets mixed with multiwall carbon nanotubes, $J$. Solid State Electrochem., 2008, 12, 1129-1134.

52 X. Wang, M. Li, Z. Chang, Y. Yang, Y. Wu and X. Liu, $\mathrm{Co}_{3} \mathrm{O}_{4} @ M W C N T$ nanocable as cathode with superior electrochemical performance for supercapacitors, ACS Appl. Mater. Interfaces, 2015, 7, 2280-2285.

53 Y. Wimalasiri, R. Fan, X. S. Zhao and L. Zou, Assembly of Ni$\mathrm{Al}$ layered double hydroxide and graphene electrodes for supercapacitors, Electrochim. Acta, 2014, 134, 127-135.

54 X. Wu, J. Zhou, W. Xing, G. Wang, H. Cui, S. Zhuo, Q. Xue, Z. Yan and S. Z. Qiao, High-rate capacitive performance of graphene aerogel with a superhigh $\mathrm{C} / \mathrm{O}$ molar ratio, $J$. Mater. Chem., 2012, 22, 23186.

55 T. W. Weng, W. Huang and K. Y. Lee, Improved electrochemical capacitive characteristics by controlling the carbon nanotube morphology and electrolyte solution concentration, Vacuum, 2008, 83, 629-632.

56 S. Sahoo and J.-J. Shim, Facile Synthesis of ThreeDimensional Ternary $\mathrm{ZnCo}_{2} \mathrm{O}_{4} /$ Reduced Graphene Oxide/ NiO Composite Film on Nickel Foam for Next Generation Supercapacitor Electrodes, ACS Sustainable Chem. Eng., 2017, 5, 241-251. 
57 L. Zhang, J. Wang, J. Zhu, X. Zhang, K. San Hui and K. N. Hui, 3D porous layered double hydroxides grown on graphene as advanced electrochemical pseudocapacitor materials, J. Mater. Chem. A, 2013, 1, 9046.

58 H. Chen, Y. Ai, F. Liu, X. Chang, Y. Xue, Q. Huang, C. Wang, H. Lin and S. Han, Carbon-coated Hierarchical Ni-Mn Layered Double Hydroxide Nanoarrays on Ni Foam for Flexible High-Capacitance Supercapacitors, Electrochim. Acta, 2016, 213, 55-65.

59 L. Zhang, K. Nam, K. San and H. Lee, High-performance hybrid supercapacitor with 3D hierarchical porous fl owerlike layered double hydroxide grown on nickel foam as binder- free electrode, J. Power Sources, 2016, 318, 76-85.

60 S. Wu, K. S. Hui and K. N. Hui, One-Dimensional Core-Shell Architecture Composed of Silver Nanowire@Hierarchical Nickel-Aluminum Layered Double Hydroxide Nanosheet as Advanced Electrode Materials for Pseudocapacitor, J. Phys. Chem. C, 2015, 119, 23358-23365.
61 O. Jankovský, P. Šimek, K. Klimová, D. Sedmidubský, S. Matějková, M. Pumera and Z. Sofer, Towards graphene bromide: bromination of graphite oxide, Nanoscale, 2014, 6, 6065-6074.

62 H. Wang, Y. Liu, M. Li, H. Huang, H. M. Xu, R. J. Hong and H. Shen, Multifunctional $\mathrm{TiO}_{2}$ nanowires-modified nanoparticles bilayer film for 3D dye-sensitized solar cells, Optoelectron. Adv. Mater., Rapid Commun., 2010, 4, 11661169.

63 C. Wu, J. Cai, Q. Zhang, X. Zhou, Y. Zhu, P. K. Shen and K. Zhang, Hierarchical mesoporous zinc-nickel-cobalt ternary oxide nanowire arrays on nickel foam as highperformance electrodes for supercapacitors, ACS Appl. Mater. Interfaces, 2015, 7, 26512-26521.

64 S. Tongay, J. Hwang, D. B. Tanner, H. K. Pal, D. Maslov and A. F. Hebard, Supermetallic conductivity in bromineintercalated graphite, Phys. Rev. B: Condens. Matter Mater. Phys., 2010, 81, 1-6. 